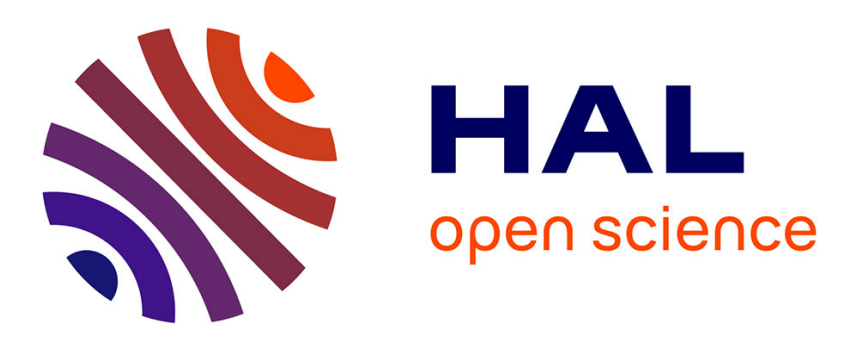

\title{
A natural biomimetic porous medium mimicking hypomineralized enamel
}

\author{
Elsa Vennat, Maud Denis, Bertrand David, Jean-Pierre Attal
}

\section{To cite this version:}

Elsa Vennat, Maud Denis, Bertrand David, Jean-Pierre Attal. A natural biomimetic porous medium mimicking hypomineralized enamel. Dental Materials, 2015, 31 (3), pp.225-234. 10.1016/j.dental.2014.12.008 . hal-01100634

\section{HAL Id: hal-01100634 \\ https://hal.science/hal-01100634}

Submitted on 29 Sep 2020

HAL is a multi-disciplinary open access archive for the deposit and dissemination of scientific research documents, whether they are published or not. The documents may come from teaching and research institutions in France or abroad, or from public or private research centers.
L'archive ouverte pluridisciplinaire HAL, est destinée au dépôt et à la diffusion de documents scientifiques de niveau recherche, publiés ou non, émanant des établissements d'enseignement et de recherche français ou étrangers, des laboratoires publics ou privés. 


\title{
A natural biomimetic porous medium mimicking hypomineralized enamel
}

\author{
Vennat E. ${ }^{1,}{ }^{*}$, Denis M. ${ }^{1,2}$, David B. ${ }^{1}$, Attal J.-P. ${ }^{2}$ \\ ${ }^{1}$ Laboratoire Mécanique des Sols, Structures et Matériaux (UMR8579), Ecole Centrale Paris, Grande Voie des Vignes \\ 92295 Chatenay Malabry, France \\ ${ }^{2}$ Unité de Recherche Biomatériaux Innovant et Interfaces (EA4462), Faculté de Chirurgie Dentaire, University Paris- \\ Descartes, 1 rue Maurice Arnoux, 92120 Montrouge, France \\ *Corresponding author. Vennat E., Laboratoire Mécanique des Sols, Structures et Matériaux, Ecole Centrale Paris, \\ Grande Voie des Vignes 92295 Chatenay Malabry Cedex, France. Tel: +33 1411316 58. E-mail address: \\ elsa.vennat@ecp.fr
}

\section{Abstract}

In order to evaluate the clinical impact of low viscosity resin infiltration in hypomineralized enamel, it is necessary to obtain a biomimetic porous substrate capable of mimicking enamel. The specifications for the biomimetic porous medium are defined using the literature data on hypomineralized enamel. Based on these specifications, we propose to use deproteinized dentin, the latter being deproteinized by heat treatment.

Thermogravimetry Analysis (TGA), Field Emission Scanning Electron Microscopy (FESEM) observations, Mercury Intrusion Porosimetry (MIP) tests and nanoindentation are performed on the deproteinized dentin tissue. Heat treatment is shown to be an effective and reproducible method for removing organic fluids and protein residues in dentin. Deproteinizing dentin also enables forming nanovoids by eliminating its organic matrix. The interconnected open nanoporosities (porosities of less than $100 \mathrm{~nm}$ ) created at $600^{\circ} \mathrm{C}$ are distributed between $14 \mathrm{~nm}$ and $32 \mathrm{~nm}$ and the total porosity is $39 \%$ (including $36 \%$ due to nanoporosities). At $800^{\circ} \mathrm{C}$, they are distributed between $60 \mathrm{~nm}$ and $100 \mathrm{~nm}$ and total porosity is $37 \%$ (including $33 \%$ arising from the nanoporosities). The hydroxyapatite crystal structure is transformed less at $600^{\circ} \mathrm{C}$, so this temperature should be preferred.

Besides providing new understanding of the dentin tissue itself, this study led to characterizing a porous medium made of natural apatite, and proposing and validating its use as a porous medium mimicking hypomineralized enamel. The next logical step of this study is the characterization of resin infiltration in this medium and its mechanical reinforcement. 
Keywords: hypomineralized enamel; biomimetics; minimally invasive dentistry; mineral porous medium; hydroxyapatite; deproteinized dentin; porosimetry; thermogravimetry; nanoindentation; SEM; tissue engineering; porous scaffold

1. Introduction

Enamel is the most mineralized tissue of the organism with a mineral component evaluated at $96 \%$ by weight and $87 \%$ by volume. However, the mineral component may be affected by certain pathologies. In the case of hypomineralization, the rate of mineralization decreases without loss of volume. In this case the enamel is called hypomineralized enamel. In hypomineralized enamel, the mineral part made up of hydroxyapatite crystals $\left(\mathrm{Ca}_{10}\left(\mathrm{PO}_{4}\right)_{6}(\mathrm{OH})_{2}\right)$ is smaller than in sound enamel, reaching only 50 to $80 \%$ by volume. At the macroscopic scale, hypomineralized enamel becomes opaque, leaving unsightly white spots. At the microscopic scale, it presents interconnected porosity (20 to $200 \mathrm{~nm}$ ) due to ultrastructure alteration (enlargement of the inter-prismatic sheath [1-2] and localized acid dissolution of intra-prismatic crystals [3]). From the mechanical standpoint, hypomineralized enamel is weaker than sound enamel because mechanical properties like hardness and elastic modulus are strongly correlated with its degree of mineralization [4-6]. Its hardness and elastic modulus are around 0.5 $\pm 0.3 \mathrm{GPa}$ and $14.5 \pm 7.5 \mathrm{GPa}[7]$, respectively, versus $3 \mathrm{GPa}$ to 6GPa and 70GPa to $115 \mathrm{GPa}$ for sound enamel [7-11].

The objective of the Resin Infiltration Technique, a new treatment fully compatible with the concept of Minimally Invasive Dentistry [12], is to mask the white lesions of hypomineralized enamel. This treatment is based on the use of a photopolymerizable low viscosity resin with a refractive index close to that of sound enamel [13-14]. Besides remaining a minimally invasive procedure [15-17], the treatment masks white opacity [1819] and reinforces the mechanical characteristics [20] of hypomineralized enamel. The mineral network initially weakened is incorporated into a resin. It forms a semi-natural biocomposite with good mechanical properties, which is what makes it such an attractive biomimetic material. Regarding the new boom in therapeutic resin infiltration, an increasing number of infiltrants are expected on the market in the coming years, making it necessary to assess and compare them. Some of them have been studied separately from the lesion or by using a porous medium mimicking the lesion [21], that is to say the characteristics obtained (contact angle, surface tension, viscosity, hardening) do not take into account the medium 
invested. To bridge this gap, our aim is to define a reliable and reproducible model mimicking most of the characteristics of hypomineralized enamel (summarized in Table 1). This makes it necessary to perform infiltration and mechanical tests on pairs of resin/biomimetic porous medium.

The use of natural hypomineralized enamel seems ideal, but as hypomineralization is not an indicator for extraction, such samples are very difficult to gather in sufficient numbers for systematic testing. Therefore artificial hypomineralized enamel [22-24] or models made of synthetic hydroxyapatite can be considered. However, these candidates must be dismissed because either they cannot provide a specimen with a calibrated volume (necessary for infiltration and mechanical tests) or the crystal form is not sufficiently close to that of natural crystal. As surprising as it may seem, deproteineized dentin could be a very interesting alternative in response to our specifications. First, dentin is formed by the same odontogenesis mechanisms as enamel. Enamel and dentin have the same hydroxyapatite chemistry. Secondly, the mineral density of dentin ( $50 \%$ by volume) is certainly lower than in sound enamel ( $87 \%$ by volume), but is still very close to that of hypomineralized enamel (60\% to $70 \%$ by volume). Thirdly, the mechanical properties of dentin [25-26] (hardness from 0.81 to $1.19 \mathrm{GPa}$ and a Young's modulus from 18 to $25 \mathrm{GPa}$ ) are close to those of hypomineralized enamel. Fourthly, the use of dentin samples offers the advantage of allowing the preparation of calibrated samples compatible with laboratory tests. However dentin presents an abundant collagen matrix (mainly composed of type I collagen fibers) strongly linked to the crystal lattice. To obtain a porous mineral medium from the dentinal substrate, we propose to deproteinize the dentin to remove the collagen fibers and only keep the mineral matrix. Given the complexity of the organic matrix, deproteinization by heat treatment seems more relevant and efficient than selective chemical deproteinization.

The objective of this study is to evaluate the morphological and mechanical consequences of dentin deproteinization by heat treatment to validate the use of deproteinized dentin as a substrate mimicking hypomineralized enamel.

2. Material and methods

\subsection{Sample preparation}


Twenty non-carious human molars, extracted according to the protocols approved by the review board of the Dental Faculty of Paris-Descartes University, were used in this study. They were stored directly in $1 \%$ chloramine-T solution. The teeth were prepared using a flat wet grinding machine (Planopol-3, STRUERS) to retain only the coronal dentin. Enamel, cementum and radicular dentin were removed. Three teeth were kept for the control group (D0). Seventeen specimens were cut vertically into two equal parts to form two equivalent groups (D600 and D800). All the specimens were also acid etched with $37 \%$ phosphoric acid for $15 \mathrm{~s}$ and then rinsed to remove the smear layer formed during the preparation procedures.

A conventional gradient ethanol dehydration process was applied to the DO specimens reserved for SEM observation, and for the specimens of groups D600 and D800. In groups D600 and D800, the samples were deproteinized by heat treatment (see next section). After the preparation procedure, all the specimens were stored in a desiccation room.

The specimens reserved for nanoindentation (Figure 1) were embedded before micron polishing. Specimens were rinsed in an ultrasound water bath (Transsonic 275, PROLABO) between each polishing step. Sound and hypomineralized enamel samples were also prepared in order to establish a comparison with the groups made from dentin. After embedding, the enamel samples and DO group samples were stored in distilled water. Samples from groups D600 and D800 were again subjected to ethanol dehydration. Sample preparation and the methodology are summarized in Figure 1.

\subsection{Deproteinization by Heat Treatment (HT)}

In groups D600 and D800, the samples were deproteinized according to the thermodynamic principle of phase transition. The deproteinization process was performed under air using the VITA INCERAMAT 3 oven. The samples were heated to $600^{\circ} \mathrm{C}(\mathrm{D} 600)$ and $800^{\circ} \mathrm{C}(\mathrm{D} 800)$, temperatures at which organic components are known to be eliminated while preserving mineral components. That is to say, the temperatures chosen were higher than $420^{\circ} \mathrm{C}$, the temperature at the organic matrix is degraded [27] and lower than $850^{\circ} \mathrm{C}$ [28], the temperature at which densification occurs due to the sintering behavior of hydroxyapatite grain.

\subsection{Thermal Analysis}


Thermogravimetry and differential thermogravimetry analysis (TGA and DTGA) were carried out specifically on D0 group samples in an STA 449 F3 Jupiter (Netzsch). The sample weight of sound dentin (D0 group) used for thermogravimetry analysis was $17 \mathrm{mg}$. A heating rate of $5^{\circ} \mathrm{C} / \mathrm{min}$ was employed for the run and the temperature range was 30 $1000^{\circ} \mathrm{C}$ in a nitrogen and oxygen atmosphere of $80 \mathrm{ml} / \mathrm{min}$ and $60 \mathrm{ml} / \mathrm{min}$, respectively.

\subsection{Field emission scanning electron microscopy}

Field emission scanning electron microscopy (FESEM) was used to compare the impact of the Heat Temperature (HT) on dentin qualitatively, especially in the crystal phase and for the porous microstructure, using an FEG LEO 1530 microscope (LEO Elektronenmikroskopie $\mathrm{GmbH}$ ) operated at low voltage (1-5 kV).

In each group, a specimen was randomly harvested and then fractured. The fractured samples were observed after being set on brass washers using a conductive coating.

\subsection{Mercury Intrusion Porosimetry (MIP)}

We used mercury porosimetry to quantify open porosity and assess the material pore size distribution. Mercury is a non-wetting liquid that will not naturally penetrate into the pore spaces of the sample. An incremental pressure was applied to the mercury so it entered the pores of the sample progressively. At each pressure step, the volume of mercury entering the sample was measured. The applied pressure $P$ was linked to the pore diameter $D$ via the surface tension of mercury $y$ and its contact angle $\theta$ using the Jurin-Laplace law:

$$
D=-\frac{4 \gamma \cos \theta}{P}
$$

A mercury porosimeter (Micromeritics Autopore IV, Micromeritics) was used with a small sample holder (penetrometer 13-0609). The sample holder containing the dentin slices was weighed using an electronic balance with an accuracy of $0.1 \mathrm{mg}$ (Sartorius TE214S, Labandco), then assembled on the porosimeter. The gas within the penetrometer was removed completely before the latter was filled with mercury under low pressure (approximately from 0.003 to $0.20 \mathrm{MPa}$, corresponding to the pore size between 420 and $6 \mu \mathrm{m})$. After removing the sample holder from the low pressure cell, the assembly (penetrometer, sample and mercury) was weighed. The different weight data were collected 
in order to use the penetrometer as a pycnometer. Then, the penetrometer (containing the sample immersed in mercury) was inserted in the high pressure cell. Pressures from 0.20 to $200 \mathrm{MPa}$ (corresponding to pore sizes between $6 \mu \mathrm{m}$ to $6 \mathrm{~nm}$ ) were applied. The volume of mercury penetrating into the sample was recorded at each pressure step. The contact angle and surface tension of mercury were set beforehand for all the tests at $130^{\circ}$ and $485 \mathrm{dyn} / \mathrm{cm}$ [29], respectively. To obtain reliable results, the manufacturer recommends a final mercury intrusion volume between 20 and $80 \%$ of the stem volume. To fulfill this condition, four samples, i.e. four half teeth, were used for each test. Four tests per group (D600 and D800) were performed: D600T1, D600T2, D600T3, D600T4 and D800T1, D800T2, D800T3, D800T4. As shown in Figure 1, groups D600 and D800 were obtained from the same teeth. The samples were fractured prior to testing in order to facilitate pore access.

\subsection{Nanoindentation}

The indentation experiments were performed using a nanoindenter (XP, MTS). The specimens were mounted on a support to ensure the exposure of a flat surface at right angles to the indenter. They were indented with a calibrated Berkovich indenter [30].

Samples of groups D0, D600 and D800 were mapped systematically with spacings of 100 $\mu \mathrm{m}$ between individual indentations, in order to scan a surface of $1 \mathrm{~mm}^{2}$, i.e. one hundred acquisitions. The indenter tip was set to apply a load of $25 \mathrm{mN}$ held for $5 \mathrm{~s}$. The forcedisplacement curve of loading and unloading was used to calculate the mechanical properties (elastic modulus and hardness) of each indentation point.

The same procedure was also reproduced on sound and hypomineralized enamel samples.

\subsection{Statistics}

Porosity and mechanical property data were analyzed using the Kruskal-Wallis test, which is useful for the 2 by 2 comparison of batches with different variances. The significance level was fixed at $p=0.05$.

3. Results

\subsection{General observation}


After HT, the dentin slices presented a color change. The specimens of groups D600 and D800 became "dark gray / bluish" and "light gray", respectively, compared to D0 which was light yellow (Figure 2).

\subsection{Thermogravimetric analysis (TGA)}

Figure 3 shows the TGA curve (sample weight as a function of temperature) obtained for the sound dentin (group D0) heated in a controlled atmosphere. It shows continuous weight loss throughout the HT. The weight loss increased substantially up to $530^{\circ} \mathrm{C}$, after which it slowed down considerably. The D0 specimen fell from $100 \%$ to $73.76 \%$, and from $73.76 \%$ to almost $72 \%$ at temperatures from $40^{\circ} \mathrm{C}$ to $530^{\circ} \mathrm{C}$ and $530^{\circ} \mathrm{C}$ to $980^{\circ} \mathrm{C}$, respectively; corresponding to a weight loss of $26.24 \%$ in the first period of $\mathrm{HT}$ and $1.76 \%$ for the second period. Weight loss after $530^{\circ} \mathrm{C}$ was insignificant.

Four peaks of weight loss can be identified on the DTGA curve (Figure 3 ) at different temperatures. The first peak weight loss can be seen at $130^{\circ} \mathrm{C}$. The weight of the specimen falls to $97.1 \%$. Another substantial weight loss peak occurs at $330^{\circ} \mathrm{C}$, with a reduction sample weight. The third peak at $450^{\circ} \mathrm{C}$ overlaps the end of the second peak. Hence, the third peak appears less marked and can be considered as part of the second peak. A weak final peak of weight loss was recorded at $710^{\circ} \mathrm{C}$

The maximum temperature at the end of each weight loss peak (DTGA curve, illustrated in Figure 3) was measured to establish the contribution of each reaction to weight loss.

\subsection{Scanning Electron Microscopy (SEM) observations}

The SEM observation allowed qualitative analysis of the interconnected porous network formed by heat treatment. Representative FESEM pictures of the control human dentin samples (group D0) and those heated to $600^{\circ} \mathrm{C}$ (group D600) and $800^{\circ} \mathrm{C}$ (group D800) are shown in Figure 4.

In the D0 group, the tubular collar surface was smooth and seemed to be impermeable except for a few scattered secondary tubules. The intertubular dentin was inhomogeneous but void-free. Group D600 exhibited greater roughness after the calcination of the dentin than group D800, revealing porosity from the peritubular dentin up to the intertubular dentin. The acicular crystal morphology and size was 
more or less preserved. On the other hand, for group D800, crystal size and morphology exhibited significant changes. The crystalline diameter was about $100 \mathrm{~nm}$ and the crystals acquired a rounded, almost spherical structure. Many voids can be observed between the spherical crystals. The sizes of the crystallites are roughly $10 \mathrm{~nm}$ and 100nm for group D600 and D800, respectively (Figure 4).

\subsection{Mercury Intrusion Porosimetry (MIP)}

We used MIP to quantitatively evaluate the effect of HT on the dentin porous network. Figure 5 presents the pore size distribution in terms of cumulative and incremental curves and clearly illustrates the effect of HT on the porosity of human dentine. Figure 6 shows the distribution of the average porosity related to pore size for each group (D0, D600 and D800).

Group D0 presents a single pore size around $0.60 \mu \mathrm{m}$ whereas group D600 and D800 present two distinct pore sizes around $0.9 \mu \mathrm{m}$ and $20 \mathrm{~nm}$ and around $0.9 \mu \mathrm{m}$ and $90 \mathrm{~nm}$, respectively. The distribution of the second pore size is different between these two groups and lies respectively between $14 \mathrm{~nm}$ and $32 \mathrm{~nm}$ and between $60 \mathrm{~nm}$ and 100 $\mathrm{nm}$ (Figure 6).

The total porosity of group D600 was recorded at 39\% $( \pm 1.2 \%)$, including $36 \%( \pm 1.4 \%)$ arising from the second porosity. It is slightly lower for D800 with a total porosity of $37 \%( \pm 3.4 \%)$, including $33 \%( \pm 3.5 \%)$ from the second porosity (Figure 7 and Table 2 ).

\subsection{Modulus of elasticity and hardness}

Hypomineralization considerably reduces the mechanical properties of enamel. The sound enamel had a hardness and an elastic modulus of $1.9 \mathrm{GPa}( \pm 0.6 \mathrm{GPa})$ and 85.5GPa $( \pm 15.7 \mathrm{GPa})$, respectively, which fell to $0.56 \mathrm{GPa}( \pm 0.40 \mathrm{GPa})$ and $27.3 \mathrm{GPa}$ $( \pm 5.7 \mathrm{GPa}$ ) when hypomineralization occurred. HT seemed to reduce the hardness of dentin slightly. Group D0 presented a hardness of $0.52 \mathrm{GPa}( \pm 0.13 \mathrm{GPa})$ versus $0.32 \mathrm{GPa}$ $( \pm 0.13 \mathrm{GPa})$ and $0.36 \mathrm{GPa}( \pm 0.10 \mathrm{GPa})$ for groups $\mathrm{D} 600$ and D800. In contrast, HT seemed to increase the local elastic modulus of dentin slightly. Group D0 presented an elastic modulus value of $19.32 \mathrm{GPa}( \pm 2.8 \mathrm{GPa})$ versus $27.32 \mathrm{GPa}( \pm 5.7 \mathrm{GPa})$ and $24.95 \mathrm{GPa}$ $( \pm 4.0 \mathrm{GPa})$ for D600 and D800 (Figure 8 ).

\section{6 Statistics}


Total porosity did not differ significantly between groups D600 and D800 ( $p>0.05)$ but the size of the nanopores revealed by heat treatment differed significantly between those groups $(p<0.05)$.

From the mechanical standpoint, groups D600, D800 and hypomineralized enamel did not differ significantly in terms of local elastic modulus and hardness $(p>0.05)$. These three groups all differed from sound enamel in terms of local elastic modulus and hardness $(p<0.05)$.

\section{Discussion}

This study aimed at validating the use of dentin deproteinized by heat treatment as a porous medium mimicking hypomineralized enamel. To fulfill this objective, thermogravimetric analysis (TGA), porosimetry tests, FESEM observations and nanoindentation tests were performed. The objective of TGA was to choose and validate the heat treatment temperature whereas the porosimetry tests and SEM observations were carried out to investigate, quantitatively and qualitatively, the porous structure revealed by deproteinization. Finally, the nanoindentation tests were performed to evaluate whether the mechanical properties of the newly formed porous medium are close enough to those of hypomineralized enamel.

First, TGA and optical microscope observations are discussed. Our results showed a color change during thermal treatment. The belated volatilization of organic residues of collagen in a calcified matrix (such as dentin) is the hypothesis advanced by numerous authors [31-33] to explain color change as a function of heating temperature. Consistent with the observations of Fan et al. [32] (dentin is amber at $200^{\circ} \mathrm{C}$, black at $400^{\circ} \mathrm{C}$, dark grey at $600^{\circ} \mathrm{C}$, light grey at $800^{\circ} \mathrm{C}$ and white at $950^{\circ} \mathrm{C}$ ), dark grey specimens were obtained after heating at $600^{\circ} \mathrm{C}$, and light grey specimens at $800^{\circ} \mathrm{C}$. This color change according to temperature was pointed out by Ooi et al. [33] in a study on bone. The persistence of a darker colors observed on dentin after heating seems to indicate incomplete removal of certain organic chemical components. These may be retained in calcined dentin in the form of oxidized residues or carbonates. Together with optical microscopy observations and in accordance with the literature [34-36], the four peaks of weight loss identified on the DTGA curve (Figure 3) can be linked to: 
- proteic denaturation due to water evaporation that breaks the hydrogen bonds and thus increases the sensitivity of the freed collagen to thermal denaturation [37] $\left(130^{\circ} \mathrm{C}\right)$,

- decomposition of the organic substrate [38] $\left(330^{\circ} \mathrm{C}\right)$,

- residual decomposition of the organic substrate $\left(450^{\circ} \mathrm{C}\right)$,

- the loss of carbonates [39] $\left(710^{\circ} \mathrm{C}\right)$.

Thus, the TGA results confirmed that dentin deproteinization occurs at high temperature (higher than $500^{\circ} \mathrm{C}$ ). The challenge to obtain specimens totally deproteinized by heat treatment at $600^{\circ} \mathrm{C}$ and $800^{\circ} \mathrm{C}$ was successful for groups D600 and D800. This was confirmed by the FESEM observations and porosimetry tests discussed below.

The porosimetry tests presented two main pore sizes around $0.9 \mu \mathrm{m}$ and $20 \mathrm{~nm}$ and around $0.9 \mu \mathrm{m}$ and $90 \mathrm{~nm}$ for groups D600 and D800, respectively, whereas control group D0 only presented one pore size around $0.6 \mu \mathrm{m}$. The first pore size detected corresponded to the tubules and microbranchings that were present in the three groups. The shift of pore size towards a larger pore size with heat treatment indicates that the tubules were affected by the heat treatment. But the main finding was that heat treatment allows the formation of new porosity following the removal of the collagen fibers (confirmed by FESEM observations). In group D600, the new pore size was around 50nm whereas in group D800, it was around $100 \mathrm{~nm}$. This difference between the two groups can be explained by the transformation of crystallites occurring at $800^{\circ} \mathrm{C}$, as could be seen in the FESEM observations. The HT did not alter dentin microstructure (tubular, peritubular and intertubular compartments), but at $600^{\circ} \mathrm{C}$, the crystals remained acicular and small while at $800^{\circ} \mathrm{C}$, the grains grew and become spherical, a phenomenon already reported by Locardi et al. [36]. As the temperature increased, a series of reactions in the non-stoichiometric HAP of the dentin occurred, marked in the case of our study by the decomposition of HAP into $\beta-$ tricalcium phosphate $(\beta-\mathrm{TCP})$ around $700^{\circ} \mathrm{C}$. For Bernache-Assollant et al. [28], hydroxyapatite crystal growth would occur even from $600^{\circ} \mathrm{C}$. The increase in crystallite size occurring during the conversion in $\beta$-TCP was responsible for a decrease in specific surface area. That explains, firstly, the increase in pore size for D800 (passing from several tens of nanometers to a hundred nanometers) and, secondly, the slight decrease of total porosity at this calcination temperature. However, it is noteworthy that the porous mineral network 
obtained remained interconnected and open despite calcination at high temperature. Finally, the crystalline transformation of HAP into TCP at a temperature higher than $700^{\circ} \mathrm{C}$ excluded the use of D800 specimens as a resin infiltration support model.

The total porosity of group D600 was recorded at 39\%, including 36\% arising from Protein Free Porosity (PFP). It was slightly lower for D800 with a total porosity of $37 \%$, including $33 \%$ from PFP (Figure 7). The total porosity of sound dentin (group D0) was much lower (4\%) because it was dependent only on tubular porosity (DTP). The porosity due to the removal of collagen fibers in groups D600 and D800 (33\% and 36\%, respectively) met our specifications in terms of porosity (set at between 20 and 40\%, as presented in Table 3). It can be seen that the natural porosity of dentin remains but its share is negligible compared to the porosity newly created by heat treatment.

In addition to validating the transformation of dentin into a satisfying mineral porous medium model by heat treatment, the experiment carried out provided interesting information on its composition and micro- and nano-structure. According to the total porosity of each group, the volume percentage of the mineral phase appears slightly underestimated in the literature [40-41], but a further study at lower temperature should be conducted to confirm this finding. Indeed, the study of dentin thermal deproteinization allowed assessing the average total porosity of deproteinized dentin (39.4\%), and, by extension, its remaining mineral volume of $60.6 \%$, whereas Driessens and Verbeeck [42] and Mjör and Fejerskov [40] indicated a mineral volume of $50 \%$ for this same substrate. However, Vennat et al. [41] showed a porosity of roughly $4 \%$ and $70 \%$ for intact and demineralized dentin, respectively, that is to say that the tubules occupy $4 \%$ of dentin volume while collagen fibers occupy $30 \%$, thus we can deduce that the mineral part is roughly $66 \%$, which is in good agreement with our findings. It is noteworthy that the results for group D800 were not taken into account here, as the sintering phenomenon at this temperature would have led to overevaluating the mineral volume.

The removal of the organic phase precluded the structural organization and the location of the apatite crystals. The average pore size obtained with D600 was lower than the average diameter of a collagen fiber (83-100nm for hydrated fibers and $75-105 \mathrm{~nm}$ for dehydrated fibers, [43]). This can be explained by the fact that crystals were not only located around the collagen fibers. The crystal is both interfibrillar and intrafibrillar, as explained by Pashley et 
al. [44]. It should also be noted that MIP detects pore entry sizes thus it can lead to an overestimation of small pore sizes.

Dentin keeps its structural integrity after complete deproteinization by heating. Therefore observation of the heated samples showed that despite the removal of their proteic phase, their volume and tubular architecture was fully preserved. As shown by Chen et al. [45] for bones, the mineral phase of dentin seems to be arranged in a continuum. The mineral phase of dentin therefore does not seem be a dispersed phase in an organic matrix.

From the mechanical point of view, the nanoindentation tests performed on the heattreated groups were also in good agreement with the specifications. Table 3 highlights the overall good agreement between the specifications and the porous medium formed. Group D600 (heat treatment up to $600^{\circ} \mathrm{C}$ ) seemed to be the most satisfying.

The mineral porous medium presented here could also be considered for its use as a scaffold in tissue engineering applications. In tissue engineering, a porous scaffold is required to receive cells and enable their growth. The optimum scaffold architecture is not known but the following design variables are key determinants:

- the provision of adequate space for growth and the development of sufficient transport pathways within the porous material,

- the ability to be broken down by osteoclasts,

- surface mechanical properties propitious for future cells (for example, soft or hard tissue).

Dentin has already been used as a bone substitute [46-47] and as a scaffold for dental tissue engineering [48], but deproteinized dentin has not yet been envisaged for this purpose to our knowledge. The porous medium made of deproteinized dentin characterized here is interesting because of its porosity (39\% for group D600), but above all because it is composed of natural hydroxyapatite [35] (instead of synthetic hydroxyapatite which is most often proposed and studied [48]). Thus it exhibits a roughness close to the aragonite shaped crystals found in coral (proven to be a very efficient scaffold for bone reconstruction [48-49]) and it is known to have an enhanced biodegradation rate compared with synthetic bioceramics. Also, its mechanical properties can make it a good candidate to stimulate cells in order to create mineralized tissues.

\section{Conclusion}


The challenge to reproduce a biomimetic porous medium to study the effect of infiltrants on hypomineralized enamel raises numerous issues. The surprising idea of deproteinizing dentin by heat treatment is attractive and it proved to be suitable in terms of porosity, pore size range and mechanical properties. The calcination temperature of $600^{\circ} \mathrm{C}$ was the most satisfying, leading to a total porosity of $39 \%$, with two pore sizes, one due to the tubules (around $0.9 \mu \mathrm{m}$ ) and one due to the elimination of the collagen fibrils (around 20nm). The porosity due to the elimination of the collagen fibrils was $36 \%$. This biomimetic porous medium should be used for evaluating the infiltration kinetics and mechanical properties of new treatments using hypomineralized dentin.

The mineral porous medium presented here can also be considered as a scaffold for tissue engineering since it is composed of natural hydroxyapatite and has interesting morphological characteristics.

\section{Acknowledgements}

The authors would like to thank Mrs. F. Garnier, Mr. T. Reiss and Mr. N. Roubier for their technical assistance in performing the SEM observations, MIP experiments and mechanical characterization, respectively.

\section{References}

1. Xie Z, Kilpatrick NM, Swain MV, Munroe PR, Hoffman M. Transmission electron microscope characterisation of molar-incisor-hypomineralisation. J Mater Sci: Mater Med 2008 ; 19:3187-3192

2. Andreasen JO, Ravn JJ. The effect of traumatic injuries to primary teeth on their permanent successors. Scand J Dent Res 1971 ; 79: 219-294

3. Palamara J, Phakey PP, Raehinger WA, Oratns HJ. Ultrastructure of the intact surface zone of white spot and brown spot carious lesions in human enamel. J Oral Pathol 1986; 15:28-35

4. Cuy JL, Mann AB, Livi KJ, Teaford MF, Weihs TP. Nanoindentation mapping of the mechanical properties of human molar tooth enamel. Arch Oral Biol $2002 ; 47(4): 281-291$

5. Xie ZH, Mahoney EK, Kilpatrick NM, Swain MV, Hoffman M. On the structure - property relationship of sound and hypomineralized enamel. Acta Biomaterialia 2007 ; 3(6):865-872

6. Huang TTY, Jones AS, He LH, Darendeliler MA, Swain MV. Characterisation of enamel white spot lesions using X-ray micro-tomography. J Dent 2007; 35:737-743

7. Mahoney EK, Rohanizadeh R, Ismail FS, Kilpatrick NM, Swain MV. Mechanical properties and microstructure of hypomineralised enamel of permanent teeth. Biomaterials $2004 ; 25(20): 5091-100$

8. Willems G, Celis JP, Lambrechts P, Braem M, Vanherle G. Hardness and Young's modulus determined by nanoindentation technique of filler particles of dental restorative materials compared with human enamel. J Biomed Mater Res 1993 ; 27:747-55

9. Habelitz S, Marshall SJ, Marshall GW, Balooch M. Mechanical properties of human dental enamel on the nanometer scale. Arch Oral Biol $2001 ; 46: 173-183$ 
10. Fong H, Sarikaya M, White SN, Snead ML. Nano-mechanical properties profiles across dentin-enamel junction of human incisor teeth. Mat Sci Eng C-Bio S $2000 ; 7$ : 119-128

11. He LH, Fujisawa N, Swain MV. Elastic modulus and stress-strain response of human enamel by nanoindentation. Biomaterials $2006 ; 27(43): 88-98$

12. Simonsen RJ. The preventive resin restoration : a minimally invasive nonmetallic restoration. Compendium $1987 ; 8: 428-430$

13. Attal JP, Atlan A, Denis M, Vennat E, Tirlet G. White spots on enamel: treatment protocol by superficial or deep infiltration (part 2). International Orthodontics 2014

14. Denis M, Atlan A, Vennat E, Tirlet G, Attal JP. White defects on enamel: diagnosis and anatomopathology: two essential factors for proper treatment (part 1). International Orthodontics $2013 ; 11(2): 139-65$

15. Kielbassa AM, Müller J, Gernhardt CR. Closing the gap between oral hygiene and minimally invasive dentistry: a review on the resin infiltration technique of incipient (proximal) enamel lesions. Quintessence Int $2009 ; 40: 663-681$

16. Tirlet G, Chabouis HF, Attal JP. Infiltration, a new therapy for masking enamel white spots: a 19-month follow-up case series. European Journal of Esthetic Dentistry 2013; 8(2):180-190

17. Muñoz MA, Arana-Gordillo LA, Gomes GM, Gomes OM, Bombarda NHC et al.. Alternative esthetic management of fluorosis and hypoplasia stains: blending effect obtained with resin infiltration techniques. J Esthet Restor Dent 2013; 25:32-39

18. Paris S, Meyze-Lueckel H. Masking of labial enamel white spot lesions by resin infiltration - A clinical report. Quintessence Int 2009 ; 40:713-718

19. Torres CRG, Borges AB, Torres LMS, Gomes IS, Simoes de Oliveira R. Effect of caries infiltration technique and fluoride therapy on the colour masking of white spot lesions. J Dent 2011; 39:202-07

20. Torres CRG, Rosa PCF, Ferreira NS, Borges AB. Effect of Caries Infiltration Technique and Fluoride Therapy on Microhardness of Enamel Carious Lesions. Oper Dent $2012 ; 37(4): 363-369$

21. Paris S, Meyer-Lueckel H, Cölfen H, Kielbassa AM. Penetration coefficients of commercially available and experimental composites intended to infiltrate enamel carious lesions. Dent Mater 2007 ; $23(6): 742$ - 48

22. Buskes JA, Christoffersen J, Arends J. Lesion formation and lesion remineralization in enamel under constant composition conditions. A new technique with applications. Caries Res 1985 ; 19:490-96

23. Celiberti $P$, Lussi A. Penetration ability and microleakage of a fissure sealant applied on artificial and natural enamel fissure caries. J Dent 2007 ; 35:59-67

24. Kantovitza KR, Pascona FM, Nobre-dos-Santosa M, Puppin-Rontani RM. Review of the Effects of Infiltrants and Sealers on Non-cavitated Enamel Lesions. Oral Health Prev Dent 2010; 8:295-305

25. Toparli M. Koksal NS. Hardness and yield strength of dentin from simulated nano-indentation tests. Comput Meth Prog Bio $2005 ; 77: 253-57$

26. Kinney JH, Balooch M, Marshall SJ, Marshall GW, Weihs TP. Hardness and Young's modulus of peritubular and intertubular dentine. Arch Oral Biol 1996 ; 41:9-13

27. Bozec L, Odlyha M. Thermal Denaturation Studies of Collagen by Microthermal Analysis and Atomic Force Microscopy. Biophys J $2011 ; 101: 228-36$

28. Bernache-Assollant $D$, Ababou A, Champion E, Heughebaert M. Sintering of calcium phosphate hydroxyapatite $\mathrm{Ca}_{10}\left(\mathrm{PO}_{4}\right)_{6}(\mathrm{OH})_{2}$ : I. Calcination and particle growth. J Eur Ceram Soc 2003; 23:229-41

29. Mikijelj B, Varela JA, Whittemore OJ. Equivalence of surface areas determined by nitrogen adsorption and by mercury porosimetry. Ceram Bull $1991 ; 70: 829-31$ 
30. Huang TTY, He LH, Darendeliler MA, Swain MV. Nano-indentation characterisation of natural carious white spot lesions. Caries Res $2010 ; 44: 101-7$

31. LeGeros RZ, Kijkowska R, Zheng R, Fan D, LeGeros JP. Effect of heat treatment on properties of human enamel and dentin (abstract). J Dent Res $1992 ; 72$ (spec iss):320

32. Fan D, LeGeros RZ, LeGeros JP. Consequence of heat-treatement on properties of dentin (abstract). J Dent Res $1995 ; 74($ spec iss):525

33. Ooi CY, Hamdi M, Ramesh S. Properties of hydroxyapatite produced by annealing of bovine bone. Ceram Int 2007; 33:1171-7

34. Holager J. Thermogravimetric Examination of Enamel and Dentin. J Dental Res $1970 ; 49(3): 546-8$

35. Figueiredo M, Fernando A, Martins G, Freitas J, Judas F, Figueiredo H. Effect of the calcination temperature on the composition and microstructure of hydroxyapatite derived from human and animal bone. Ceram Int $2010 ; 36(8): 2383-93$

36. Locardi B, Pazzaglia UE, Gabbi C, Profilo B. Thermal behaviour of hydroxyapatite intended for medical applications. Biomaterials $1993 ; 14(6): 437-41$

37. Armstrong SR, Jessop JLP, Winn E, Tay FR, Pashley DH. Denaturation Temperatures of Dentin Matrices. I. Effect of Demineralization and Dehydration. J Endodont 2006 ; 32(7):638-41

38. Sakae T, Mishima H, Kozawa Y, Legeros RZ. Thermal Stability of Mineralized and Demineralized Dentin: A Differential Scanning Calorimetric Study. Connect Tissue Res 1995; 33:193-96

39. Nordback IG, Johansen E, Parks HF. Effect of heat on the carbonate content of dentin. J Dent Res 1961 ; 40:704

40. Mjor IA, Fejerskov O. Histology of the Human Tooth, $2^{\text {nd }}$ edn. Munksgaard, Copenhagen, 1979

41. Vennat E, Bogicevic C, Fleureau JM, Degrange M. Demineralized dentin 3D porosity and pore size distribution using mercury porosimetry. Dent Mater $2009 ; 25(6): 729-35$

42. Driessens FCM, Verbeeck RMH. Biominerals. Taylor \& Francis, CRC Press, 1990, pp. 163-178

43. Habelitz S, Balooch M, Marshall SJ, Balooch G, and Marshall GWJ. In situ atomic force microscopy of partially demineralized dentin collagen fibrils. J Struct Biol 2002 ; 138:227-36

44. Pashley DH, Tay FR, Breschi L, Tjäderhane L, Carvalho RM, Carrilho M et al..State of the art etch-and-rinse adhesives. Dent Mater $2011 ; 27(1): 1-16$

45. Chen PY, Toroian D, Price PA, McKittrick J. Minerals Form a Continuum Phase in Mature Cancellous Bone. Calcified Tissue Int $2011 ; 88(5): 351-61$

46. Bormann KH, Suarez-Cunqueiro MM, Sinikovic B, Kampmann A, von See C, Tavassol F et al.. Dentin as a suitable bone substitute comparable to ß-tcp---an experimental study in mice. Microvasc Res 2012 ; 84(2):116-22

47. Jiao L, Xie L, Yang B, Yu M, Jiang Z, Feng L et al.. Cryopreserved dentin matrix as a scaffold material for dentin-pulp tissue regeneration. Biomaterials $2014 ; 35(18): 4929-39$

48. Petite H, Viateau V, Bensaid W, Meunier A, de Pollak C, Bourguignon L et al.. Tissue-engineered bone regeneration. Nature biotechnology 2000, 18(9):959-963

49. David B, Bonnefont-Rousselot D, Oudina K, Degat MC, Deschepper M, Viateau V et al.. A perfusion bioreactor for engineering bone constructs: an in vitro and in vivo study. Tissue Engineering Part C: Methods $2011 ; 17(5): 505-516$ 
